\title{
From Learning Style of Webpage Content to Learner's Learning Style
}

\author{
Mohamed.G. Darwesh ${ }^{1}$, Magdy .Z. Rashad², Abdelaziz. K. Hamada ${ }^{2}$ \\ ${ }^{1}$ Faculty of Computers and Information, Cairo University \\ ${ }^{2}$ Faculty of Computer and Information Systems, Mansoura University \\ Gdarwishemcit.gov.eg, magdi_z2011@yahoo.com, Abdelaziz2020@gmail.com
}

\begin{abstract}
Technology plays an important role in the development of students who can search for the concepts which they learn in the books on the Internet and find out more information on them. This will increase the depth of their knowledge.

According to some researches, students tend to be more active and more participative when technology is being integrated in their lesson resulting to better comprehension and good performance.

Using technology in the learning process can facilities automatic detection of the learner's learning styles which can help the learner to develop his coping strategies to compensate for his/her weaknesses, capitalize on his/her strengths, improve the quality of the learning process and make it more effective.

This research presents an automatic tool for detecting learning styles in a learning environment by analyzing the content of the learner's favorite WebPages using social bookmarking services(www.tagme1.com) and shows that how actual behavior of the learners during the learning process can be used as an effective source for detecting their learning styles based on Felder-Silverman learning style model (FSLSM).
\end{abstract}

Keywords: Learning style, e-Learning, Social software, PLE, Adaptive Web Education

\section{Introduction}

E-learning refers to all forms of electronically supported learning and teaching and essentially the computer and network-enabled transfer of skills and knowledge. Moreover, e-learning can be done anywhere and anytime as long as the user has the proper hardware.

Learning styles are various approaches or ways of learning. They involve education methods, particular to an individual, which are presumed to allow that individual to learn best. Most people prefer an identifiable method of interacting with, taking in, and processing information.

Everyone has a learning style, and as a learner it may be of great benefit for you to know what your particular style may be. Knowing how to absorb and retain information may help you recognize your strong points as well as your not-so-strong areas. The benefit? It can help you when it comes to deciding how best to study for an exam, for example, read a book or write a paper.

Over the past years, the field of automatic detection of the learner's learning style has been of a considerable international interest. There are many tests available to help you and your learners discover your best learning style and we presented a tool that is able to provide teachers and learners with better information about their learning styles. 
By automatic detection of the learner's learning style, an adaptive learning system will be able to support individual learning and provide customized learning according to the individual differences, improve the quality of e-learning process, make learning easier for students and increase their learning progress.

Our proposed tool presents automatic detection of the learner's learning style by following and analyzing his/her behavior through his/her interactions with the contents of web pages using social bookmarking software such as tag me site.

This paper is structured as follows. First, we present Felder-Silverman learning style model. Second, we introduce the index of learning styles. In the next section, we introduce our System overview and its stages as follows: Pre-Processing (data collection), choosing patterns / features, choosing model (learning style model), calculating learner's learning style and the Evaluating our proposed system

\section{Background and related work}

\subsection{Felder-Silverman's learning styles model}

Felder-Silverman's learning style model (1988) seems to be the most appropriate for use in computer-based educational systems (Carver et al., 1999, Kuljis and Liu, 2005). Most other learning style models classify learners in few groups, whereas FSLSM describes the learning style of a learner in more detail, distinguishing between preferences on four dimensions as follows:

\begin{tabular}{|c|l|}
\hline Dimension & \multicolumn{1}{|c|}{ Definition } \\
\hline Verbal & $\begin{array}{l}\text { Get more out of words-written and spoken } \\
\text { explanations }\end{array}$ \\
\hline Visual & $\begin{array}{l}\text { Remember best what they see-pictures, diagrams, } \\
\text { flow charts, time lines, films, and demonstrations }\end{array}$ \\
\hline Sequential & $\begin{array}{l}\text { Gain understanding in linear steps } \\
\text { Follow logical stepwise paths in finding solutions }\end{array}$ \\
\hline Global & $\begin{array}{l}\text { Learn in large jumps } \\
\text { Solve complex problems quickly once they have } \\
\text { grasped the big picture }\end{array}$ \\
\hline Active & $\begin{array}{l}\text { Understand information best by doing something } \\
\text { with it,Like group work }\end{array}$ \\
\hline Reflective & $\begin{array}{l}\text { Understand information best by thinking about it } \\
\text { quietly first ,Prefer to work alone }\end{array}$ \\
\hline Sensing & $\begin{array}{l}\text { Like learning facts } \\
\text { Solve problems by well-established methods and } \\
\text { dislike complications }\end{array}$ \\
\hline Intuitive & $\begin{array}{l}\text { Prefer discovering possibilities and relationships } \\
\text { Like innovation and dislike repetition }\end{array}$ \\
\hline
\end{tabular}

Table 1: Felder-Silverman learning style model dimensions

\subsection{Index of learning styles}

The Index of Learning Styles (ILS), developed by Felder and Soloman, is a 44-item questionnaire for identifying the learning styles according to FSLSM. 
Each learner has a personal preference for each dimension. These preferences are expressed with values between +11 to -11 per dimension. This range comes from the 11 questions that are posed for each dimension. When answering a question, for instance, with an active preference, +1 is added to the value of the active/reflective dimension whereas an answer for a reflective preference decreases the value by 1 . Therefore, each question is answered either with a value of +1 (answer a) or -1 (answer b).

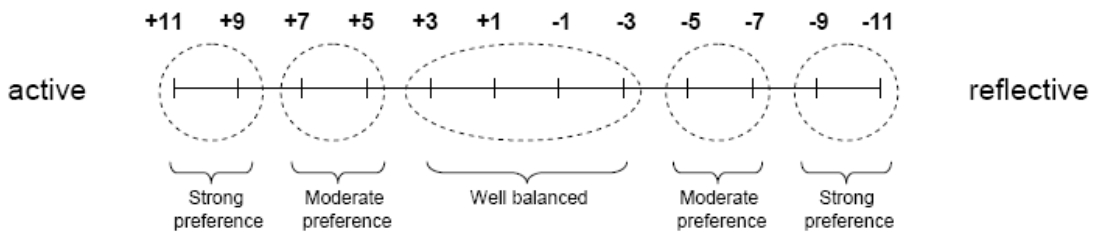

Figure 1.Scales of the dimensions examples

\subsection{Learning Vector Quantization}

Learning Vector Quantization (LVQ) is a supervised version of vector quantization that can be used when we label input data, and it is considered a method for training competitive layers in a supervised manner. A competitive layer automatically learns to classify input vectors. However, the classes that the competitive layer finds are dependent only on the distance between input vectors. If two input vectors are very similar, the competitive layer probably will put them in the same class. LVQ networks, on the other hand, learn to classify input vectors into target classes chosen by the user as shown as figure 2 .

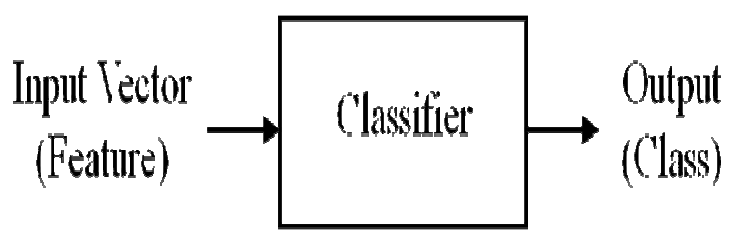

Figure 2. LVQ network overview

\subsubsection{LVQ Basic Algorithm}

Step 0: Initialize the reference vectors

Step 1: While termination condition is not satisfied

Step 1.1: For each training input pattern $\mathbf{x}$

Step 1.1.1: Find $\mathrm{j}$ such that $\left\|\mathbf{x}-\mathbf{w}_{\mathrm{j}}\right\|$ is minimum among all output nodes

Step 1.1.2:Update $\mathbf{w}_{\mathbf{j}}$ based on whether the output node's class matches the input vector's class

$\mathbf{x}$.

If $\operatorname{class}(\mathbf{x})==\operatorname{class}\left(\mathbf{w}_{\mathbf{j}}\right)$ then $\mathbf{w}_{\mathbf{j}}=\mathbf{w}_{\mathbf{j}}+\mathrm{h}\left(\mathbf{x}-\mathbf{w}_{\mathbf{j}}\right)$

If class $(\mathbf{x}) !=\operatorname{class}\left(\mathbf{w}_{\mathbf{j}}\right)$ then $\mathbf{w}_{\mathbf{j}}=\mathbf{w}_{\mathbf{j}}-\mathrm{h}\left(\mathbf{x}-\mathbf{w}_{\mathbf{j}}\right)$

Step 1.2: Reduce the learning rate 


\subsubsection{Sensitivity of Base LVQ Classifier}

The changes of parameters of the LVQ network structure have a high impact on the classification result. We use a learning rate as an example in the next section and show how the recognition rate effected by changing of learning rate.

\section{- Learning rate}

Learning rate is a critical parameter that affects greatly on the recognition process. The best learning rate increases the learning process. Our experiments try a different number of learning rate $(0.01,0.05,0.1,0.5$, and 0.9$)$ in existence of 150 epochs and 40 hidden neurons, as shown in

table 2.

\begin{tabular}{|c|c|c|}
\hline \multicolumn{2}{|l|}{ Alpha } & 0.01 \\
\hline \multicolumn{2}{|l|}{ Epochs } & 150 \\
\hline Hidden Neurons & No of Learners & Recognition Rate \\
\hline \multirow[t]{2}{*}{20} & 25 & $64.00 \%$ \\
\hline & 15 & $93.33 \%$ \\
\hline \multirow[t]{2}{*}{40} & 25 & $72.00 \%$ \\
\hline & 15 & $93.33 \%$ \\
\hline \multirow[t]{2}{*}{60} & 25 & $72.00 \%$ \\
\hline & 15 & $93.33 \%$ \\
\hline \multirow[t]{2}{*}{80} & 25 & $72.00 \%$ \\
\hline & 15 & $93.33 \%$ \\
\hline \multirow[t]{2}{*}{100} & 25 & $72.00 \%$ \\
\hline & 15 & $93.33 \%$ \\
\hline
\end{tabular}

Table.2. Examination results of the recognition rate based on different values for Alpha

\subsubsection{Ensemble LVQ for LS Identification}

We present an ensemble LVQ for LS identification system structure by using majority voting that outperforms the best classifier. As shown on figure 3 .

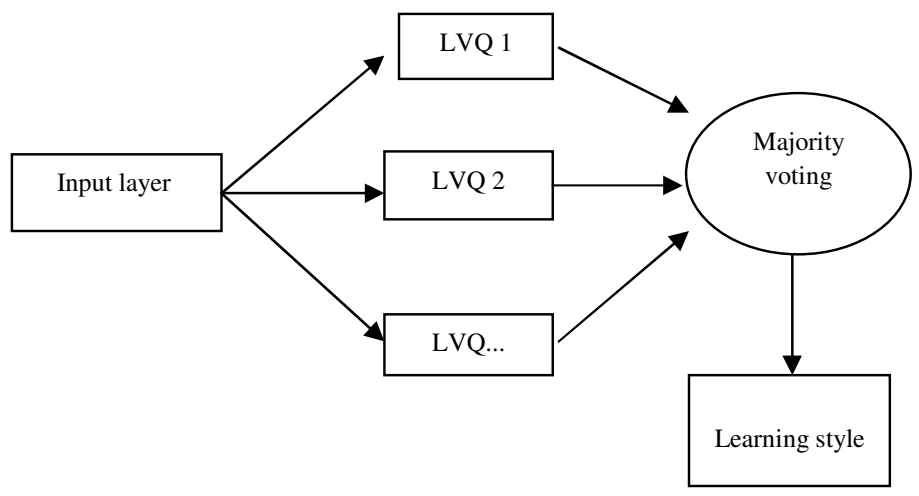

Figure 3. LVQ for LS identification system structure 


\subsection{Related work}

Much work and a great number of studies investigate the relationships between the learners' learning styles and their reaction within learning environments and they present an automatic approach for detecting learning style such as Graf et al. (2007a) that proposes an automatic student modeling approach for LMSs for detecting learning style preferences according to the Felder-Silverman learning style model (FSLSM) (Felder \& Silverman, 1988). The proposed approach is based on patterns related to those features, implemented in most LMSs and used by teachers and course developers like content objects, outlines, self-assessment tests, exercises, examples and discussion forums and time spent on visited content objects. Then, the relevance of these patterns to each dimension of learning style is described, and using a simple rule-based method the learners' behavior is related to their preference of semantic groups (Graf et al., 2007a). Ebru Özpolat and Gözde B. Akar (2010) present an automatic detection of learning styles for an e-learning system and they address the problem of extracting the learner model based on Felder-Silverman learning style model. The target learners in this problem are the ones studying basic science. Using NBTree classification algorithm in conjunction with Binary Relevance classifier, learners are classified based on their interests. Then, the learners' learning styles are detected using these classification results. Experimental results are also conducted to evaluate the performance of the proposed automated learner modeling approach.

Nowadays, the main concern in e-learning is to improve the learning process and many research papers indicate that this is possibly done through an adaptive system. Hanan (2005) states that "There are many attempts to improve the adaptive system by using different methods and artificial intelligence techniques for extracting user model and overcoming the difficulties".

\section{The proposed tool}

In this section, we present our proposed tool that is easy for learners to use, for automatic detection of learning styles. Our approach integrates information about learning styles, social software, to help educational systems to provide personalized and more efficient adaptation based on learning styles. The general form of detecting learning style tool architecture is illustrated in Figure 2 which is composed of the following several basic stages:

a. Pre-Processing (Data collection):

This stage includes collecting raw data of learners and preparing his/her behavior's database.

b. Dimension of learning style model relevant keywords

In this stage, we assume a sample of relevant keywords for each dimension of FSLSM learning style model.

c. Model Choice (Learning style model)

At this stage we choose the Felder-Silverman learning style model,

d. Calculating learner's learning style,

- Keywords provide indications about learning styles,

- All indication values were summed up where information was available,

- The results were normalized on a range from 0 to 1

$0 \ldots$ the learner has a strong negative preference for this learning style

1 ... the learner has a strong positive

preference for this learning style

e. Evaluation

- Learners filled out the ILS questionnaire using tagme site (www.tagme1.com) 
- Results of ILS were compared with the results of our approach based on a 2-item scale (e.g. between an active and reflective learning style),

- Measuring the efficiency of the results of the proposed tool, the correct identification of the learner's learning style as well as how close the predicted learning style to the learning style that is based on the ILS values, the following measure was proposed by García et al. (2007)

$$
\text { Precision }=\frac{\sum_{i=1}^{n} \operatorname{Sim}\left(L S_{\text {predicted }}, L S_{\text {ILS }}\right)}{n} \cdot 100
$$

\subsection{Data collection}

The learner's interactions with tagme website were tracked in order to get information about their learning behavior. Data are stored in tagme database for each learner. For example, a table includes data about each link of a learner and the description of it. We extract raw data from each table at bookmarks database related to each learner's behavior.

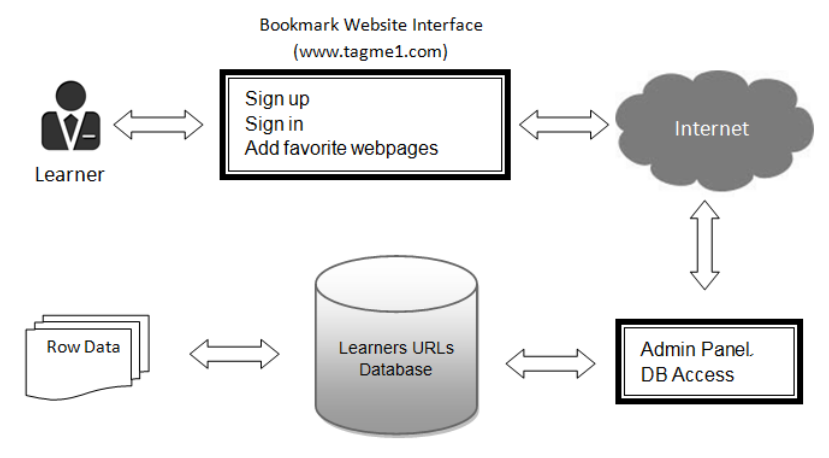

Figure 4.Data collection process

\subsection{Learning style model choice}

We chose Felder and Silverman's model (1988) that describes the learning styles by using scales from +11 to -11 for each dimension for the following reasons:

- The most appropriate for educational systems,

- Describes the learning style in more detail,

- Represents also balanced preferences,

- Describes tendencies.

\subsection{Calculation of Learning Styles}

Learning styles are calculated from the raw data taken from data extraction component at Section3.1. Learning styles are calculated in this way for each dimension based on the ordered 
International Journal of Computer Science \& Information Technology (IJCSIT) Vol 3, No 6, Dec 2011

data. Ordered data for each pattern can take the values 1, 0 indicating, for instance, a low or strong state. Ordered data for each pattern can also take the values 1, 0 indicating a low or strong state.

\section{Experimental and results}

\section{1)Learning Rate}

Our experiments try a different number of learning rate $(0.01,0.05,0.1,0.5$, and 0.9$)$ in existence of 150 epochs and 40 hidden neurons, as shown in table (3) and Figure (5).

\begin{tabular}{|c|c|c|}
\hline \multicolumn{2}{|l|}{ Hidden neurons } & 40 \\
\hline \multicolumn{2}{|l|}{ Epochs } & 150 \\
\hline \multirow{2}{*}{ Alpha } & No of Learners & Recognition Rate \\
\hline \multirow{2}{*}{0.01} & 25 & $68.00 \%$ \\
\cline { 2 - 3 } & 15 & $93.33 \%$ \\
\hline \multirow{2}{*}{0.05} & 25 & $68.00 \%$ \\
\cline { 2 - 3 } & 15 & $93.33 \%$ \\
\hline 0.1 & 25 & $68.00 \%$ \\
\cline { 2 - 3 } & 15 & $86.66 \%$ \\
\hline 0.5 & 25 & $52.00 \%$ \\
\cline { 2 - 3 } & 15 & $86.66 \%$ \\
\hline 0.9 & 25 & $52.00 \%$ \\
\cline { 2 - 3 } & 15 & $93.33 \%$ \\
\hline
\end{tabular}

Table.3. Examination results of the recognition rate based on different values for Alpha.

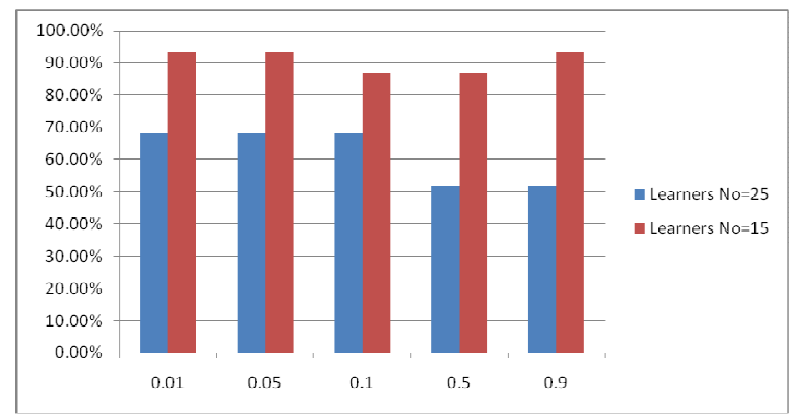

Figure 5. Examination results based on different values of learning rate, Alpha. 
International Journal of Computer Science \& Information Technology (IJCSIT) Vol 3, No 6, Dec 2011

\section{2) Number of Hidden Neurons}

Increasing the hidden neurons is consider one of the most parameters related to complexity of the network, increasing the learning time and recognition rate of the network, as shown in table(4) and Figure (6).

\begin{tabular}{|c|c|c|}
\hline \multicolumn{2}{|l|}{ Alpha } & 0.01 \\
\hline \multicolumn{2}{|l|}{ Epochs } & 150 \\
\hline \multirow{2}{*}{ Hidden Neurons } & No of Learners & Recognition Rate \\
\hline \multirow{2}{*}{20} & 25 & $64.00 \%$ \\
\cline { 2 - 3 } & 15 & $93.33 \%$ \\
\hline \multirow{2}{*}{40} & 25 & $72.00 \%$ \\
\cline { 2 - 3 } & 15 & $93.33 \%$ \\
\hline \multirow{2}{*}{60} & 25 & $72.00 \%$ \\
\cline { 2 - 3 } & 15 & $93.33 \%$ \\
\hline \multirow{2}{*}{80} & 25 & $72.00 \%$ \\
\cline { 2 - 3 } & 15 & $93.33 \%$ \\
\hline \multirow{2}{*}{100} & 25 & $72.00 \%$ \\
\hline & 15 & $93.33 \%$ \\
\hline
\end{tabular}

Table 4. Examination results of the recognition rate based on different values for hidden neurons

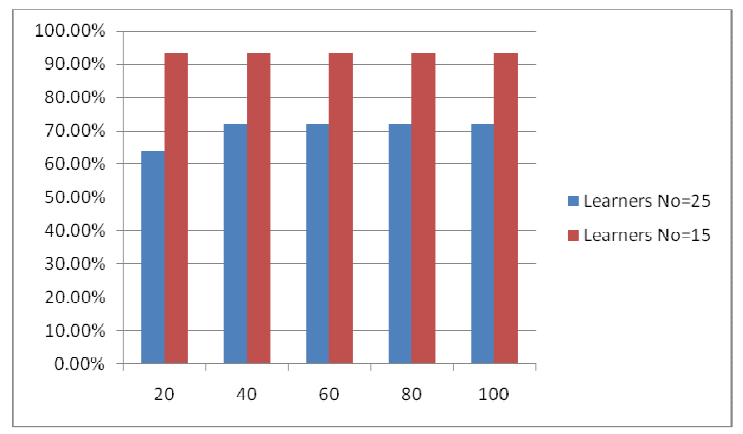

Figure 6. Examination results based on different values of hidden neurons

\section{3) Values for Epochs}

Our experiments try many different numbers of epochs (100, 150, 200, 250 and 300 epochs), as shown in Table (5) and Figure (7). 
International Journal of Computer Science \& Information Technology (IJCSIT) Vol 3, No 6, Dec 2011

\begin{tabular}{|c|c|c|}
\hline \multicolumn{2}{|l|}{ Hidden neurons } & 40 \\
\hline \multicolumn{2}{|l|}{ Alpha } & 0.1 \\
\hline \multirow{2}{*}{ Epochs } & No of Learners & Recognition Rate \\
\cline { 2 - 3 } & 250 & $68.00 \%$ \\
\cline { 2 - 3 } & 15 & $93.33 \%$ \\
\hline \multirow{2}{*}{150} & 25 & $72.00 \%$ \\
\cline { 2 - 3 } & 15 & $93.33 \%$ \\
\hline \multirow{2}{*}{200} & 25 & $72.00 \%$ \\
\cline { 2 - 3 } & 15 & $93.33 \%$ \\
\hline \multirow{2}{*}{250} & 25 & $80.00 \%$ \\
\cline { 2 - 3 } & 15 & $93.33 \%$ \\
\hline & 25 & $80.00 \%$ \\
\hline & 15 & $93.33 \%$ \\
\hline
\end{tabular}

Table 5. Examination results of the recognition rate based on different values for epochs

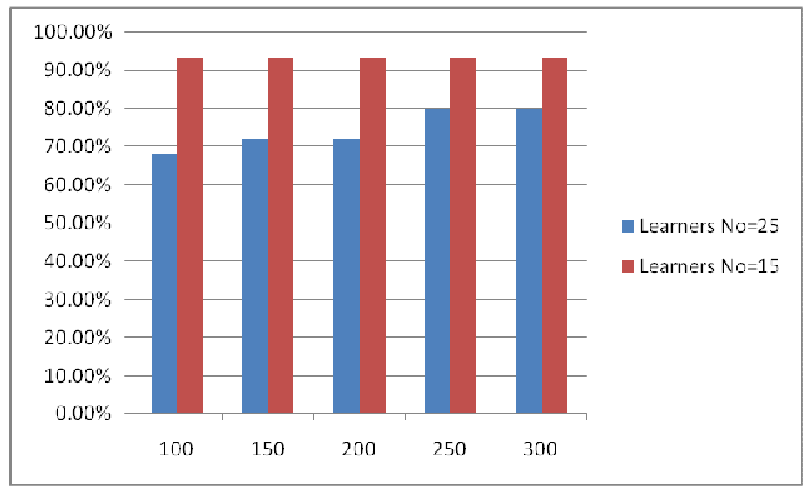

Figure 7. Examination results based on different values of epochs

\section{Conclusion and future work}

This paper presented an automatic tool for detecting learning styles in learning environment using this social bookmarking service shows how the actual behavior of learners during browsing the web can be used as an effective source for detecting their learning styles based on Felder-Silverman Learning Style Model (FSLSM).

This tool has the potential to overcome some problems of detecting learning styles based on using questionnaires. Such problems include the students' lack of motivation to fill out the questionnaire and questionnaires are static and describe the learning style of a student at a specific point in time.

In the proposed tool, no additional effort is needed on the students' part in order to enable the system to get information about their learning styles. They just have to use the system for learning in order to provide the relevant information about their behavior. 
This tool will help students to better understand their learning processes and motivate teachers to extend their teaching strategies or materials if they do not support different learning styles.

Future work will deal with the potential of improving the selected patterns and the selected relevant keywords of FSLSM dimension, improving and evaluating the reliability of our proposed tool in order to provide teachers and learners with better information.

The ability to integrate this tool with other e-learning systems such as social networks software and learning management systems (LMS) provides adaptivity to LMS.

\section{References}

1. Ebru Özpolat, Gözde B. Akar.( 2009). Automatic detection of learning styles for an e-learning system, Computers \& Education 53 (2009) 355-367.

2. David Adrian Sanders and Jorge Bergasa-Suso.Inferring Learning Style From the Way Students Interact With a Computer User Interface and the $W W W$, IEEE Transactions on Education. Vol. 53, no. 4, pp. 613-620. Nov 2010

3. Wikipedia, the free encyclopedia. [Online]. http://en.wikipedia.org/wiki/HTML

4. Nabila Bousbia, Jean-Marc Labat, and Amar Balla, (2008). Detection of Learning Styles from Learner's Browsing Behavior During E-Learning Activities. ITS 2008, LNCS 5091, pp. 740-742, 2008. (C) Springer-Verlag Berlin Heidelberg 2008

5. Farman Ali Khan, Sabine Graf, Edgar R. Weippl and A Min Tjoa , Integrated Approach for the Detection of Learning Styles \& Affective States, World Conference on Educational Multimedia, Hypermedia \& Telecommunications EDMEDIA 2009, Honolulu, Hawaii; 22.06.2009 - 26.06.2009; in: "Proceedings of ED-MEDIA 2009", (2009), S. 753 - 761.

6. Nabila Bousbia, Amar Balla, Issam Rebai,Measuring the Learners' Learning Style based on Tracks Analysis in Webbased Learning , 978-1-4244-4671-1/09/2009 IEEE

7. Graf, S, Kinshuk, \& Liu, T.-C. (2009). Supporting Teachers in Identifying Learners' Learning Styles in Learning Management Systems: An Automatic Student Modelling Approach, Educational Technology \& Society, 12 (4), 3-14.

8. Sabine Graf, Kinshuk, Tzu-Chien Liu ,Identifying Learning Styles in Learning Management Systems byUsing Indications from Learners' Behaviour, Eighth IEEE International Conference on Advanced Learning Technologies 2008 , 978-0-7695-3167-0/2008 IEEE

9. Graf, S.(2007). Adaptivity in Learning Management Systems Focusing on Learning Styles. Ph.D Thesis, Vienna University of Technology.

10. Felder, R.M. and Soloman, B.A., 1997, Index of Learning Styles questionnaire. Retrieved 10 August, 2007, from http://www.engr.ncsu.edu/learningstyles/ ilsweb.html.

11. Graf, S., Kinshuk.(2006). An Approach for Detecting Learning Styles in Learning Management Systems, Proceedings of the International Conference on Advances Learning Technologies (ICALT 06), 161-163.

12. Nabila Bousbia, Jean-Marc Labat, Issam Rebai , Amar Balla(2008). How to determine the Learners' Learning Styles in e-Learning Situation?, Proceedings of The 16th International Conference on Computers in Education ICCE 2008 , 185-186

13. C. Pahl. 2006. Data Mining for the Analysis of Content Interaction in Web-based Learning and Training Systems. Data Mining in E-Learning

14. S. Graf, Kinshuk, Enabling Learning Management Systems to Identify Learning Styles, Proceedings of the International Conference on Interactive Computer Aided Learning", (2006), ISBN: 3-89958$195-4$ 
International Journal of Computer Science \& Information Technology (IJCSIT) Vol 3, No 6, Dec 2011

15. C. Pahl, Learning Style Identification in E-Learning Environments using Data Mining Technology, Proc. EnCKompass Workshop, 01-JAN-02 - 31-DEC-02

16. Nor Bahiah Hj Ahmad, Siti Mariyam Shamsuddin,A Comparative Analysis of Mining Techniques for Automatic Detection of Student's Learning Style, 10th International Conference on Intelligent Systems Design and Applications, 978-1-4244-8136-1/10/2010 IEEE

17. García, P., Amandi, A., Schiaffino, S. and Campo, M., 2007. Evaluating Bayesian networks' precision for detecting learners' learning styles. Computers \& Education, Vol. 49, No. 3, pp. 794808.

18. Gomes, A. Santos, A., Carmo, L., \& Mendes, A. J. (2007). Learning styles in an e-learning tool. In International conference on engineering education (ICCE 2007).

19. Carver, C. A., Howard, R. A., \& Lane, W. D. (1999). Addressing different learning styles through course hypermedia. IEEE Transactions on Education, 42(1), 33-38.

20. Felder, R. M., \& Brent, R. (2005). Understanding student differences. Journal of Engineering Education, 94(1), 57-72.

21. RichardM.Felder,BarbaraA.Solomon.Learning styles and Strategies ,http://www4.ncsu.edu/unity/lockers/users/f/felder/public/Learning_Styles.html

22. R.M. Felder and L.K. Silverman, Learning and teaching styles in engineering education, Engineering Education, 78, 1988, pp. 674-681. Preceded by a preface in 2002

23. S. Graf and Kinshuk, "Providing Adaptive Courses in Learning Management Systems with Respect to Learning Styles", Proceedings of the World Conference on E-Learning in Corporate, Government, Healthcare, and Higher Education (eLearn), AACE, 2007, pp. 2576-2583.

24. A.P. Rovai and K.T. Barnum, "On-line course effectiveness: an analysis of student interactions and perceptions of learning”, Journal of Distance Education,18 (1), 2003, pp. 57-73.

25. H.J. Cha, Y.S. Kim, S.H. Park, T.B. Yoon, Y.M. Jung, and J.-H. Lee, “Learning Style Diagnosis Based on User Interface Behavior for the Customization of Learning Interfaces in an Intelligent Tutoring System", Proceedings of the 8th International Conference on Intelligent Tutoring Systems, Lecture Notes in Computer Science, Berlin, Heidelberg, Springer, Vol. 4053, 2006, pp. 513-524.

26. A.P. Rovai and K.T. Barnum, "On-line course effectiveness: an analysis of student interactions and perceptions of learning”, Journal of Distance Education, 18 (1), 2003, pp. 57-73.

27. Ahmad, N., Shamsuddin, S.M.: Analyzing Learning Preferences From E-learning Activities. In: Elearning Technology and Applications, UTM Press (2008).

28. Lo J. and Shu P. (2005) 'Identification Of Learning Styles Online by Observing Learners' Browsing Behaviour Through A Neural Network', British Journal of Educational Technology. Vol 36 No 1. pp 43-55.

29. Cha, H.J., Kim, Y.S., Lee, J.H. and Yoon, T.B. An Adaptive Learning System With Learning Style Diagnosis Based On Interface Behaviors, Workshop Proceedings of International Conference on ELearning and Games, Hangzhou, China, April 17-19 2006. pp. 513-524 (2006)

30. Alfonseca, E., Carro, R. M., Martín, E., Ortigosa, A., and Paredes, P. (2006). The Impact of Learning Styles on Student Grouping for Collaborative Learning: A Case Study, User Modeling and UserAdapted Interaction, 16 (3-4), 377-401.

31. Gomes, A. Santos, A., Carmo, L., \& Mendes, A. J. (2007). Learning styles in an e-learning tool, In International conference on engineering education (ICCE 2007). 